\title{
Title Abbreviations
}

Bridge

Loving

Ghost

Shadow

Heroes

TLG

"Wings"
This Bridge Called My Back

Loving in the War Years

Giving Up the Ghost

Shadow of a Man

Heroes and Saints

The Last Generation

"Waiting in the Wings" 
THIS PAGE INTENTIONALLY LEFT BLANK 